NBER WORKING PAPER SERIES

\title{
BOYS NAMED SUE: DISRUPTIVE CHILDREN AND THEIR PEERS
}

\author{
David N. Figlio \\ Working Paper 11277 \\ http://www.nber.org/papers/w11277 \\ NATIONAL BUREAU OF ECONOMIC RESEARCH \\ 1050 Massachusetts Avenue \\ Cambridge, MA 02138 \\ April 2005
}

I am grateful to the National Science Foundation for research support, to Dale Ballou, Steve Levitt, Diane Whitmore, participants at the AEA and AEFA annual meetings, and seminar participants at the National Bureau of Economic Research for helpful comments, and to an unnamed school district for providing me with the data necessary to conduct this project. All errors are my own. The views expressed herein are those of the author(s) and do not necessarily reflect the views of the National Bureau of Economic Research.

C2005 by David N. Figlio. All rights reserved. Short sections of text, not to exceed two paragraphs, may be quoted without explicit permission provided that full credit, including $\odot$ notice, is given to the source. 
Boys Named Sue: Disruptive Children and their

David N. Figlio

NBER Working Paper No. 11277

April 2005

JEL No. I2

\begin{abstract}
$\underline{\text { ABSTRACT }}$
This paper proposes an unusual identification strategy to estimate the effects of disruptive students on peer behavior and academic outcomes. I suggest that boys with names most commonly given to girls may be more prone to misbehavior as they get older. This paper utilizes data on names, classroom assignment, behavior problems and student test scores from a large Florida school district in the school years spanning 1996-97 through 1999-2000 to directly study the relationship between behavior and peer outcomes. I find that boys with female-sounding names tend to misbehave disproportionately upon entry to middle school, as compared to other boys and to their previous (relative) behavior patterns. In addition, I find that behavior problems, instrumented with the distribution of boys' names in the class, are associated with increased peer disciplinary problems and reduced peer test scores, indicating that disruptive behavior of students has negative ramifications for their peers.

David N. Figlio

Department of Economics University of Florida

Gainesville, FL 32611-7140

and NBER

figlio@ufl.edu
\end{abstract}




\section{Boys Named Sue: Disruptive Children and their Peers}

"Some gal would giggle and I'd get red/ And some guy'd laugh and I'd bust his head./ I tell ya, life ain't easy for a boy named Sue." --“A Boy Named Sue”, by Shel Silverstein, performed by Johnny Cash (1969)

In the 1999-2000 round of the Schools and Staffing Surveys conducted by the U.S. Department of Education, nearly half of all surveyed teachers in the United States reported that student misbehavior in their school interfered with their ability to teach effectively, and a similar fraction stated that student disrespect toward teachers is a "serious" or "moderate" problem in their school. Teachers expressed unhappiness with student misbehavior and disrespect at a higher rate than expressed concern with student apathy, students coming to school unprepared to learn, or lack of parental involvement. The typical teacher reported having to interrupt class more than twice per day to deal with student disruptions, and nearly one-fifth of teachers reported student disruptions that interrupted their teaching at least hourly. And one in five teachers argue that their principals do not enforce the rules of student conduct. Student disruption is correlated with low teacher morale: Teachers reporting disruption to be a problem in their school are more than three times as likely to say that they "definitely plan to leave teaching as soon as I can" and are one-third less likely to state that they will continue to teach "as long as I am able."

School administrators apparently agree with teachers about the perils of disruptive children in the classroom. Half of the schools in the Schools and Staffing Survey have programs for disruptive students, and 40 percent of teachers participate in annual professional development in classroom management and student discipline. 
It is clear from the survey data that many teachers, school districts and states view classroom disruption as a significant problem that interferes with their jobs and, consequently, the education of the peers of disruptive children. Lazear (2001) presents theoretical results suggesting that classroom disruption could strongly interfere with student outcomes, and can more than counteract any educational benefits accruing due to reduced class sizes.

Yet while the potential presence of peer effects in education has been studied extensively over the past decade, with a few prominent examples of recent papers including Angrist and Lang (2002), Evans, Oates and Schwab (1992), Hanushek, Kain and Rivkin (2002), Sacerdote (2000) and Zimmerman (2002), the question of whether disruptive children influence peer learning and behavior in school has gone unstudied. To date, the study that most closely addresses this question is Hoxby's (2000) analysis of the effects of additional male students in a classroom on student outcomes, the argument being that male students are more likely to disrupt the learning environment than are female students. And Gaviria and Raphael (2001) investigate whether school-level peer effects lead to juvenile delinquency and other behaviors, but do not consider whether delinquent behavior spills over to peer academic performance. One explanation for the lack of research on the effects of disruptive children on their classmates involves data; there exist few opportunities to link disruptive children to their classmates in the existing datasets. But it is also the case that it is particularly difficult to disentangle the effects of disruptive children from non-random selection; if low-performing students are more likely to 
misbehave, and children are either grouped by ability within a school or otherwise selfselect into classrooms by ability, then any finding of an effect of disruptive children on peer performance or behavior could be spurious.

I propose an unusual identification strategy to estimate the effects of disruptive students on peer behavior and academic outcomes. I suggest that boys with names most commonly given to girls may be more prone to misbehavior as they get older. The argument goes as follows: Up until a certain point in childhood, boys with names associated with girls are unaffected by their names, either positively or negatively. But as they enter middle school and (1) become more aware of their own sexuality and (2) are mixed with a new group of children (including those older than they are) who did not attend their elementary school, boys with names associated with girls may begin to misbehave in school at a disproportionate rate. The data bear this out: In the large Florida school district that provided me with the data for this analysis, in elementary school there is no relationship between names and boys' behavior, but in sixth grade, the first year of middle school in this school district, a large gap emerges in behavior between boys with names associated with girls and other boys. I therefore propose boys' names as an instrument for misbehavior in sixth grade; given that behavior problem differentials did not exist prior to sixth grade, there is no reason to suspect non-random selection into classrooms by boys with names associated with girls. ${ }^{1}$ However, the evidence described in this paragraph (and presented in more detail below) suggests that boys' names may have substantial first-stage explanatory power.

\footnotetext{
${ }^{1}$ I treat a name as "feminine" if it is empirically shown to be given more frequently to girls than to boys. I have experimented with more restrictive thresholds of sex ratios in naming, and the results reported herein are insensitive to these changes in specification.
} 
I utilize data on names, classroom assignment, behavior problems and student test scores from a large Florida school district in the school years spanning 1996-97 through 19992000. While I am unable to identify the school district in question due to confidentiality reasons, I can state that I observe 76,795 students in 159,874 student-year pairs. The observed population is evenly split between males and females. Because I know which classes each child takes from the child's academic history transcript, I can identify the child's peer group in each year. Since I have access to discipline records, I can proxy for misbehavior using student suspension data. While this is not a perfect measure of classroom disruption, it seems a reasonable proxy, and is supported by my own classroom observation and interviews with teachers and school personnel. ${ }^{2}$ And I can measure student test scores in grades three through six on a nationally norm-referenced examination. I find that, as suggested above, boys with female-sounding names tend to misbehave disproportionately in sixth grade, as compared to other boys and to their previous (relative) behavior patterns. In addition, I find that behavior problems, instrumented with the distribution of boys' names in the class, are associated with increased peer disciplinary problems and reduced peer test scores, indicating that disruptive behavior of students has negative ramifications for their peers.

\footnotetext{
${ }^{2}$ In addition, the National Educational Longitudinal Survey of 1988 allows me to empirically investigate the correlation between children who are suspended at school and children who misbehave in the classroom. In this survey, tenth-grade students report whether they have been suspended from school and two of their teachers report how often students are "disruptive" or "inattentive." I find that students who have been suspended are more than twice as likely to be considered "frequently disruptive" or "consistently inattentive in class" are are students who have not been suspended, and that this very high correlation persists even when comparing students with comparable test scores or parental education levels. Similar questions were asked of teachers in eighth grade, but I do not know about students' eighth grade suspension levels; I merely know whether or not they have been sent to the office multiple times for misbehavior, a strong correlate to suspension in the tenth-grade NELS data. Here too, I find that eighth graders who have been sent to the office for misbehavior are dramatically more likely to be considered disruptive by their teachers. Therefore, suspensions seem to be strong proxies for classroom disruption.
} 


\section{Boys named Sue?}

I seek to explore the relationship between the number of disruptive children in a classroom and the outcomes of the other children in the classroom. Specifically, my fundamental research question is whether disruptive children adversely affect their peers' performance or induce bad peer behavior. My basic regression equation is

$(\text { Outcome })_{\mathrm{ig}}=\alpha_{\mathrm{i}}+\beta_{\mathrm{g}}+\gamma \mathrm{P}_{\mathrm{ig}}+\theta \mathrm{D}_{\mathrm{ig}}$

for student $\mathrm{i}$ in grade g. Because I observe multiple years of data for individual students, I control for student fixed effects and grade fixed effects. The coefficient of interest is $\theta$, the coefficient on the fraction of a student's classmates who are disruptive (measured by the fraction who get suspended at least once for five or more days.) I control for other observed peer characteristics (the vector P)—the fraction of classmates who are Black, the fraction of classmates who are immigrants, the fraction of classmates who are lowincome (as proxied by free lunch eligibility), the fraction of classmates who are male and the average third grade test score of the student's classmates. ${ }^{3}$

However, as mentioned above, there is ample reason to expect that there would be simultaneity between a student's outcomes and the rate of classroom disruption. I propose classmates' names as an instrument for the rate of classroom disruption. My first-stage, therefore, is

\footnotetext{
${ }^{3}$ In the cases in which a student has multiple classes, I average the student's class attributes together. The results are not sensitive to taking simple averages of the classes or weighted averages of the classes based on student enrollment in each class.
} 
$\mathrm{D}_{\mathrm{ig}}=\eta_{\mathrm{i}}+\lambda_{\mathrm{g}}+\varphi \mathrm{P}_{\mathrm{ig}}+\phi \mathrm{N}_{\mathrm{ig}}$

where $\mathrm{N}$ is the fraction of a child's male classmates who have names more commonly given to girls than to boys. That is, I instrument for the rate of disruptive behavior among classmates using the fraction of boys in the classroom with feminine names. In the following subsection, I demonstrate that the first-stage relationship between names and behavior is stronger in sixth grade than in elementary grades, so I therefore also instrument using the fraction of classmates with feminine names interacted with a dummy variable for the sixth grade. ${ }^{4}$

I do not suggest that there is a causal effect of names on behavior, but rather merely wish to exploit the exogenous variation in classmate names as an indicator for classmate disruptive behavior. The remainder of this section documents the likely exogeneity of this variation.

\section{Classifying boys' names}

I adopt an agnostic approach to measuring the "femininity" of a boys' name. I consider a boy's name to be associated with girls if it is empirically observed to be given to girls more frequently than boys. Just under two percent of boys have names that are more frequently given to girls than to boys, suggesting that a child will share a class with a boy with a feminine name in about one of three classes. Among the boys' names given overwhelmingly to girls, the most commonly given in the state of Florida between 1989

\footnotetext{
${ }^{4}$ I also estimate models in which I identify the effects of disruptive peers solely using this interaction, and the "main effect" of the fraction of boys in the classroom with "feminine" names is included in both the first and second stages.
} 
and $1994^{5}$ are, in order, Alexis (given 90 percent of the time to girls), Courtney (94 percent), Shannon (92 percent), Kelly (93 percent), Shelby (95 percent) and Ashley (99 percent). Among the broader set of names given more frequently to girls than to boys, the most common names are Taylor (71 percent female), Dominique (66 percent), Alexis (90 percent), Jamie (81 percent), Ariel (80 percent) and Courtney (94 percent). These names are all reasonably common; the name Taylor is observed among boys at the same rate as Derek, Nathan and Paul, while the name Dominique is observed among boys at the same rate as Darrell, Lucas or Max. These names are, however, much more popular for girls, with Taylor appearing as frequently as Elizabeth, Emily and Megan and Dominique appearing as frequently as Catherine, Julia and Paige. Historically, many of these names were not as sex-linked as they are today: For instance, in the 1990 Census's lists of American name popularity, regardless of age, males are named Taylor at twice the rate of females, and males and females are named Ariel at about the same rates. The rate of feminine names being given to boys in this school district (1.9 percent) is very similar to the state of Florida in general (1.9 percent) and to the United States as a whole (1.8 percent), according to Social Security Administration data.

The presence of Dominique among the top "female" names for boys may call into question the effeminacy of the names in question; after all, Dominique Wilkins was among the National Basketball Association's top players at the time when the children in this study were born. To ensure that names of sports stars are not driving my results, I estimated all regressions reported below both with and without any boys' names typically given to girls but also given to any athlete who were either among the top 25 salaried

\footnotetext{
${ }^{5}$ These figures come from birth vital records data provided by the Florida Department of Health.
} 
players in the National Basketball Association, Major League Baseball or National Football League or played in that league's All-Star Game in any year during the 1990s. ${ }^{6}$ The results presented below are not substantively affected by excluding these names shared by top professional athletes; indeed, the results are slightly stronger when "feminine" athletes' names are omitted from the analysis. The results presented in the paper, therefore, treat all "feminine" boys' names the same.

Another concern with the use of "feminine" names as a proxy for behavior is that these names are somewhat more common among immigrant children and native-born English language learners than they are in the general population. But immigrants and English language learners may also have a difficult time assimilating with the remainder of their class or may be treated differently, and their presence may also affect peer behavior and performance. To ensure that this possibility is not driving the results, I control for the share of classmates who are immigrants (or native-born English language learners) in both the first and second stages of the model. It turns out that the results are unaffected by the inclusion or exclusion of controls for immigrant or English language learner peers.

I begin by exploring whether boys with names typically given to girls differ systematically along other attributes than do boys with names that are generally given to boys. I find that boys with feminine names are eight percent more likely to be lowincome (as proxied by free lunch status) than are those with names typically given to boys. This difference, however, is entirely due to the racial differences of the students. Holding constant student race, boys with feminine names are only one percent more

\footnotetext{
${ }^{6}$ These names are Ashley, Dominique and Shannon.
} 
likely to be low-income than are other boys, and among African-Americans, the difference is less than one percent. Boys with feminine first names are also slightly more likely to be immigrants; therefore, I control for the racial, ethnic, immigrant and socio-economic composition of the classroom in both my first and second stages of the model.

\section{Names and behavior}

Figure 1 plots the likelihood that a child will be suspended for at least five days on at least one occasion, by grade, sex, and, for boys, the gender-orientation of the name, for children in the unnamed school district between 1996-97 and 1999-2000. ${ }^{7}$ One observes that, across the board, few children get into serious trouble in third or fourth grade, but that in fifth grade the rate of serious trouble increases considerably, and this rate continues to increase in sixth grade. The bottom line in the figure is for girls; unsurprisingly, girls are less likely to get into serious trouble than are boys, regardless of grade. The next two lines represent the serious disciplinary rate of boys. It is clear that boys with feminine names track the rest of the male population almost perfectly through fifth grade, but in sixth grade boys with feminine names are about one-third more likely than boys in general to get into serious trouble. The top two lines perform the same analysis for African-American boys. As with boys in general, African-American boys with feminine names follow almost identical disciplinary paths on average as do AfricanAmerican boys in general. But again in sixth grade, these two groups begin to differ dramatically, with African-American boys with feminine names around one-third more

\footnotetext{
${ }^{7}$ I also investigate alternative definitions of misbehavior. I observe very similar patterns of results when using different definitions of misbehavior, as described below.
} 
likely than African-American boys in general to get into serious trouble in school. Indeed, the general pattern observed for boys is driven by African-American boys; White boys with feminine names continue to track the population of White boys in general. This general pattern supports the notion that the gender orientation of names could be used to explain behavior problems in school.

One possible explanation for the fact that African-American boys with feminine names are apparently more affected by their names than are White boys with feminine names is that these names may send a stronger signal in the African-American community than in the White community. In the African-American community, the distribution of first names is considerably less concentrated than in the White community, so there are fewer “common" names. But feminine African-American boys' names tend to be very popular for White girls, which may lead to an additional sense of alienation for African-American boys with feminine names.

As mentioned above, boys with effeminate first names are somewhat more likely to be immigrants than are boys with names typically given to boys. However, there is reason to believe that the results presented below are not sensitive to this fact. For one, the pattern of misbehavior among immigrant boys with effeminate names tracks very closely the pattern of misbehavior among native boys with effeminate names. And for AfricanAmerican boys, immigrants with names typically given to girls tend to misbehave less than do native boys with feminine names. In addition, I explicitly control for the immigrant status of classmates in both my first and second stages of the regression. 
Taken together with the descriptive information presented above, these results suggest that differential selection is not a major factor in explaining the first stage of my regression.

This sentiment is bolstered by the fact that there is reason to suspect that, at least for African-American boys, the relationship between name and behavior is related to the names of the girls in the school. African-American boys with feminine names who do not share their name with any female contemporaries at their school increase their suspension behavior by six percentage points between fifth and sixth grade. But those who share a name with a female school-mate increase their suspension behavior by 16 percent. Those who attend a school with three or more girls with their same first name increase their suspension behavior by 22 percent. African-American boys with feminine names who have at least one girl in their grade with their same name increase their suspension behavior by 21 percent, and those (albeit only six students) with three or more eponymous girls in their same grade increase their suspension behavior by 32 percent! It is apparent, therefore, that African-American boys appear sensitive to having female school-mates with their same name, and tend to misbehave at greater rates in such a circumstance.

\section{Exogenous assignment to classrooms}

In order for this to be a valid instrumenting strategy, there must be evidence that boys with feminine names are approximately randomly assigned to classrooms. This appears to be the case: As Table 1 shows, there is no apparent relationship between a student's 
ability level and his or her likelihood of sharing a class with a boy with a feminine name. The numbers reported in this table are the fractions of the male peers with feminine names for children of different measured ability types. This table shows that the likelihood that a child across the ability spectrum (as measured by third grade mathematics test scores) will have a male classmate with a feminine name is approximately equal in third grade, and remains uniform through grades four through six. No differences are ever statistically significant at the ten percent level. In grade six, the fraction of male classmates with feminine names falls for all student groups because sixth graders tend to have a larger number of peers by virtue of the fact that they take multiple classes, often with different classmates. The fact that my instrumental variable does not vary across ability groups, either in cross-section or over time, increases the credibility of its use as an instrument in the present context.

Likewise, the evidence suggests that boys with feminine names tend to have similar elementary school achievement levels to boys with more masculine names. In elementary school, African-American boys with feminine names averaged in the $42^{\text {nd }}$ national percentile in mathematics, while African-American boys with names typically given to boys averaged in the $40^{\text {th }}$ national percentile. White boys with feminine names averaged in the $74^{\text {th }}$ national percentile in mathematics, while white boys with names typically given to boys averaged in the $73^{\text {rd }}$ national percentile. Therefore, in elementary school, boys with feminine names look extremely similar to boys with more masculine names in terms of key observables. 
First stage estimates of the relationship between gender orientation of names and discipline problems

The first column of Table 2 presents estimates of the first stage of the instrumental variables regression. One observes no evidence of a differential rate of suspensions among boys prior to grade six, but in sixth grade this gap widens considerably (as evidenced by the large, statistical coefficient on the interaction term). The other coefficient estimates in the first stage regression are unsurprising: Classrooms with more African-American or male students have more disciplinary problems in general, as do classes with lower average third-grade test scores, my proxy for initial ability levels.

The second column of Table 2 presents an augmented first stage estimate, in which I estimate separate effects of the rate of African-American boys with feminine names and this variable's interaction with a sixth grade dummy variable. One observes that the firststage results are clearly due to African-American boys, rather than boys in general. These results empirically support the supposition made earlier that children with male peers with feminine names are also likely to experience greater rates of disciplinary problems in their classroom, particularly if their male classmates with feminine names tend to be African-American. The names of a child's peers has strong independent explanatory power in predicting the likelihood that that child's peers will get into trouble in school, with the partial r-squared associated with names equaling 0.03 in the model that does not distinguish between African-American boys with feminine names and other boys with feminine names, and 0.08 in the model that makes this distinction. 
One can interpret the first-stage coefficients presented in Table 2 as elasticities of classmates' behavior with respect to their names. In specification 1, an increase in the fraction of male classmates with effeminate names of two percent is associated with an increase in the observed rate of classroom disruption of two-fifths of one percent. Specification 2 suggests a larger elasticity of approximately one for African-American males, implying a doubling of the fraction of African-American boys with effeminate names is associated with a doubling of the fraction of disruptive children in the classroom. These first-stage elasticities are similar in magnitudes to the raw data presented in Figure 1: African-American boys with effeminate names are four percentage points more likely than American-American boys in general to be disruptive in sixth grade, as compared to the overall rate of disruption among all boys of six percent or the overall rate of disruption in general of just over four percent. The overall percentage increase in suspensions, therefore, predicted to come about through this channel is $0.02 \mathrm{x}$ $1 \times 0.04=0.0008$ (where 0.02 is the rate of effeminate names in the male population, 1 is the elasticity of classroom disruption with respect to effeminate names, and 0.04 is the overall rate of classroom disruption observed in the population.)

\section{Instrumental Variables Regression Results}

Table 3 presents the second-stage results of the instrumental variables model described above. Each column represents two different dependent variables: (1) the propensity of a given child to him- or herself be suspended at least once for at least five days, and (2) the national percentile ranking of that child's mathematics score on a nationally normreferenced test such as the Iowa Test of Basic Skills or the Stanford Achievement Test- 
8. ${ }^{8}$ In each model, I control for student fixed effects, grade dummies, and controls for classmate attributes (the fraction African-American in a class, the fraction male in a class, the fraction immigrant in a class, the fraction low-income in a class, and the average third-grade test score of a student's classmates.) Each of the four columns in Table 3 represents a different combination of instruments employed and main effects controlled for.

Specification 3 in Table 3 presents the results of the model in which I use both the fraction of male classmates with feminine names and its interaction with sixth grade as instruments for the fraction of students who are disruptive. The coefficient estimates, taken literally, would represent the estimated effects of moving from zero percent to 100 percent of the student's classmates being disruptive, so are not directly interpretable. To put these estimates in perspective, in a typical classroom of 30 students, the estimates suggest that adding one additional disruptive child to the classroom results in reduced peer mathematics test scores of 2.2 national percentiles and a 3.2 percentage point increased likelihood that a peer will him- or herself get into serious trouble at school, as measured by being suspended at least once for five or more days. These estimated effects are substantial in magnitude as well as being statistically significant.

In model specifications not presented in the paper but available on request, I experimented with models that treated the relationship between the fraction of disruptive children in the classroom and the peer outcomes as nonlinear. However, I could find no evidence that this relationship is either quadratic or reflects some type of "tipping"

\footnotetext{
${ }^{8}$ I cannot reveal the precise examination because it may identify the school district.
} 
model, and instead, all models indicated that the relationship, at least through sixth grade, is linear. It may be the case that in higher grades where the rate of disruptive behavior may potentially be even greater, the relationship is nonlinear, but at least through sixth grade this does not appear to be the case.

Specification 4 in Table 3 reports the results of the same basic identification strategy, but this time I control for the fraction of male classmates with feminine names, identifying the instrumental variables model only off of the interaction with sixth grade. The estimated effects of disruptive children on their peers' outcomes are nearly identical, with the coefficient estimates indicating that adding one more disruptive student to a classroom is associated with 2.2 national percentiles lower peer mathematics performance and 2.9 percentage points increased likelihood of peers getting into trouble themselves.

Specifications 5 and 6 in Table 3 use as instruments both the fraction of all boys in the class with feminine names and the fraction of African-American boys in the class with feminine names, given that the first stage appears to be driven mainly by AfricanAmerican boys, rather than all boys. Specification 5 includes the main effects of these variables as instruments, while Specification 6 controls for them in both the first and second stage, and identifies the instrumental variables model off of the interaction terms with sixth grade. As before, the results are large and statistically significant, and comparable in magnitude to those reported above (with the math score results somewhat larger): Adding one more disruptive child to the classroom is estimated to lead to 2.7 to 
4.0 national percentiles lower peer mathematics performance and 2.9 to 3.3 percentage points increased likelihood that peers will be suspended at least once for five or more days.

\section{Alternative measures of classroom disruption}

A student being suspended for five or more days is a strong indicator of classroom disruption. However, it is important to determine whether the instrumental variables results are sensitive to alternative measures of disruptive behavior. Therefore, I repeat specification (6) from Table 3 (the specification with the strongest first stage explanatory power) using two alternative measures constructed from disciplinary records-whether a classmate has been suspended at least once, and whether a classmate has had two or more disciplinary incidents in a year's time. The instrumental variables coefficient on classroom disruption in the peer suspension of five or more days specification is 0.57 (standard error $=0.06$ ) to 0.82 (standard error $=0.08$ ), depending on the measure of disruption, and the coefficient on classroom disruption in the mathematics test score specification is -75.85 (standard error $=7.02$ ) or -106.58 (standard error $=8.93$ ), depending on the measure of disruption. Therefore, at least across several different measures of classroom disruption, the results remain consistent.

\section{Sex differences in outcomes}

It is possible that disruptive classmates may have differential impacts on their peers depending on the sex of the peer. One would expect that a disruptive classmate that inhibits teacher instruction and peer concentration would likely lead to similar learning 
problems for male and female peers. However, it is uncertain whether this same disruptive classmate's behavior would have similar behavioral effects on peers. On the one hand, since boys are more prone to behavioral problems in school than are girls, one might expect that the presence of a disruptive classmate would have a larger effect on male peers' behavioral outcomes than on female peers' behavioral outcomes. But on the other hand, if girls are less likely to themselves be disruptive unless others in the class are also disruptive, one might expect a larger effect on girls than on boys. In Table 4 I repeat the instrumental variables models separately for boys and girls. For simplicity, this is the model reported in Specification 6 of Table 3, in which I identify the instrumental variables model exclusively off of the interactions between sixth grade and both the fraction of male classmates with feminine names and the fraction of African-American male classmates with feminine names. All other control variables (student fixed effects, grade dummies, peer characteristics, the fraction of male classmates with feminine names and the fraction of African-American male classmates with feminine names) are included in both the first and second stages.

One observes that the first stage coefficients on the instrumental variables are remarkably similar for both boys and girls, which is reassuring because this first stage should not differ across these two groups. However, the second stage coefficients on the fraction of disruptive classmates do differ by sex. Adding one more disruptive classmate to a classroom is associated with 3.97 national percentiles lower mathematics test scores for male peers and 4.03 national percentiles lower mathematics test scores for female peers. But while adding one more disruptive classmate to a classroom is estimated to increase 
the likelihood of male peer misbehavior by 3.9 percentage points, it is estimated the likelihood of female peer misbehavior by 2.5 percentage points. Given that girls are half as likely as boys to be disruptive, in percentage terms the estimated effects of disruptive classmates on peer behavior are somewhat larger for girls than for boys.

\section{Conclusion}

This paper presents the first empirical evidence of the effects of disruptive classmates on their peers' performance. I find that disruptive classmates apparently reduce overall mathematics achievement and increase the likelihood that other classmates will become disruptive and experience behavioral problems as well. The results indicate that boys and girls alike suffer academically from the presence of disruptive classmates, and that boys are particularly prone to misbehave when their classmates are disruptive.

These results suggest that children in classrooms with more disruptive children may require additional remediation, perhaps via smaller class sizes or more experienced teachers. I do not have information on teacher experience in my dataset, and class sizes in this school district do not vary appreciably within a grade level in a school, so I cannot directly test for whether these remedies would offset the negative effects of classroom disruption, but I intend to pursue these questions in future work.

The results also suggest a potential role for early prevention of disruptive children. I have identified a boy's name as a possible early-warning flag of disruptive behavior in middle school, and there are surely other pre-indicators of classroom disruption that I 
have not uncovered. It may be beneficial for schools to seek to determine the variables that predict future classroom disruption and either schedule classes with this in mind or actively seek to remediate potentially disruptive children before they become so. It is not obvious how to do this, but understanding the precursors to classroom disruption may help states and school districts to develop more effective classroom disruption prevention programs, the outcomes of which could—given the results presented in this paper—bear substantial fruit. 


\section{References}

Angrist, Josh and Kevin Lang (2002). "How Important are Classroom Peer Effects: Evidence from Boston's METCO Program.” National Bureau of Economic Research working paper 9263.

Evans, William, Wallace Oates and Robert Schwab (1992). "Measuring Peer Group Effects: A Study of Teenage Behavior,” Journal of Political Economy, 966-991.

Gaviria, Alejandro and Stephen Raphael (2001). "School Based Peer Effects and Juvenile Behavior," Review of Economics and Statistics, 257-268.

Hanushek, Eric, John Kain and Steven Rivkin (2002). "New Evidence about Brown v. Board of Education: The Complex Effects of School Racial Composition on Student Achievement." Working paper, Stanford University.

Hoxby, Caroline (2000). "Peer Effects in the Classroom: Learning from Gender and Race Variation.” National Bureau of Economic Research working paper 7866.

Lazear, Edward (2001). "Educational Production," Quarterly Journal of Economics, 777-803.

Sacerdote, Bruce (2000). "Peer Effects with Random Assignment." Quarterly Journal of Economics, 681-704.

Zimmerman, David (2002). "Peer Effects in Academic Outcomes: Evidence from a Natural Experiment." Review of Economics and Statistics, 9-23. 


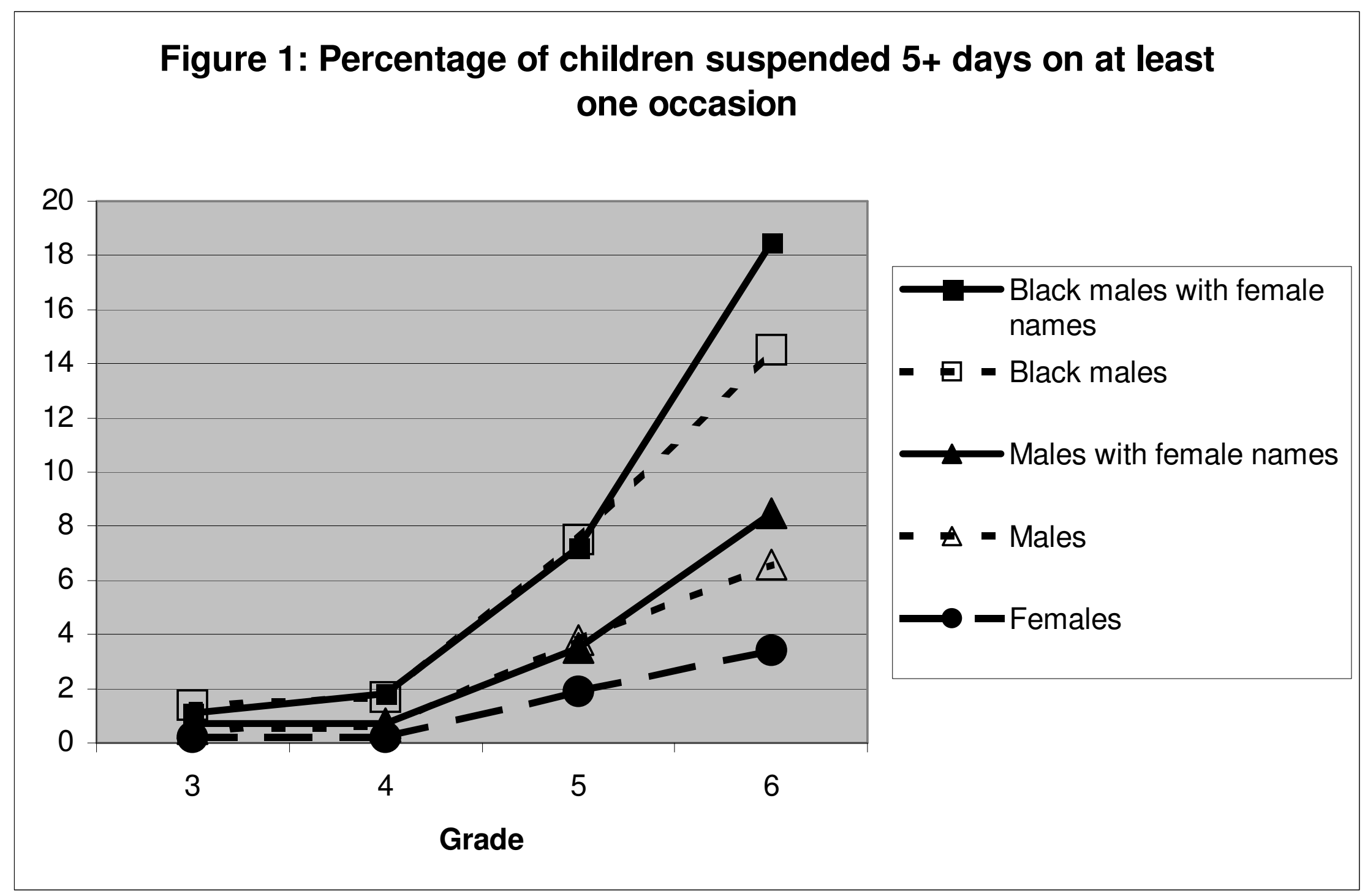


Table 1

Fraction of male classmates with feminine names, by student type and grade

\begin{tabular}{|l|l|l|l|l|}
\hline \multirow{2}{*}{ Student type } & \multicolumn{4}{|c|}{ Grade } \\
\cline { 2 - 5 } & 3 & 4 & 5 & 6 \\
\hline $\begin{array}{l}\text { Bottom quartile } \\
\text { of third grade math test distribution }\end{array}$ & 0.018 & 0.017 & 0.017 & 0.012 \\
\hline Second quartile & 0.017 & 0.015 & 0.015 & 0.013 \\
\hline Third quartile & 0.016 & 0.016 & 0.014 & 0.012 \\
\hline Top quartile & 0.016 & 0.017 & 0.015 & 0.013 \\
\hline
\end{tabular}

Note: None of the numbers in any column are statistically distinct from one another at the ten percent level. 
Table 2

First-stage estimates of the relationship between boys with female names and the rate of classroom disruption faced by students

Dependent variable: Fraction of classmates suspended at least once for 5+ days

\begin{tabular}{|l|l|l|}
\hline & \multicolumn{2}{l|}{ Specification } \\
\hline & $(1)$ & $(2)$ \\
\hline Child fixed effects & YES & YES \\
\hline Grade dummies & YES & YES \\
\hline Fraction of male classmates with female names & 0.003 & 0.000 \\
& $(0.013)$ & $(0.011)$ \\
\hline Fraction of African-American male classmates with female names & & 0.033 \\
& & $(0.026)$ \\
\hline Fraction of male classmates with female names x grade 6 & 0.226 & -0.270 \\
& $(0.040)$ & $(0.026)$ \\
\hline $\begin{array}{l}\text { Fraction of African-American male classmates with female names x } \\
\text { grade 6 }\end{array}$ & & 1.056 \\
\hline $\begin{array}{l}\text { Average third grade national percentile ranking of classmates } \\
\text { (coefficient x 10) }\end{array}$ & -0.003 & -0.003 \\
\hline Fraction of classmates who are African-American & $(0.000)$ & $(0.000)$ \\
\hline Fraction of classmates who are male & 0.036 & 0.034 \\
& $(0.002)$ & $(0.002)$ \\
\hline Fraction of classmates who are free-lunch eligible & 0.042 & 0.038 \\
& $(0.004)$ & $(0.004)$ \\
\hline Fraction of classmates who are immigrants & 0.013 & 0.010 \\
& $(0.002)$ & $(0.002)$ \\
\hline Partial r-squared of female names variables & -0.017 & -0.016 \\
& $(0.002)$ & $(0.002)$ \\
\hline
\end{tabular}

Notes: Standard errors adjusted for clustering are in parentheses beneath coefficient estimates. Data are for students in grades three through six. 
Table 3

Instrumental variables estimates of

the effect of disruptive classmates on student outcomes

\begin{tabular}{|c|c|c|c|c|}
\hline & \multicolumn{4}{|c|}{ Specification } \\
\hline & (3) & (4) & (5) & (6) \\
\hline Child fixed effects & YES & YES & YES & YES \\
\hline Grade dummies & YES & YES & YES & YES \\
\hline $\begin{array}{l}\text { Controls for } \\
\text { fraction Black, } \\
\text { third grade scores, } \\
\text { fraction males, low } \\
\text { income, } \\
\text { immigrants among } \\
\text { peers }\end{array}$ & YES & YES & YES & YES \\
\hline $\begin{array}{l}\text { Controls for } \\
\text { fraction of male } \\
\text { classmates with } \\
\text { female names }\end{array}$ & $\mathrm{NO}$ & YES & $\mathrm{NO}$ & YES \\
\hline $\begin{array}{l}\text { Controls for } \\
\text { fraction of Black } \\
\text { male classmates } \\
\text { with female names }\end{array}$ & NO & $\mathrm{NO}$ & $\mathrm{NO}$ & YES \\
\hline $\begin{array}{l}\text { Instruments } \\
\text { employed }\end{array}$ & $\begin{array}{l}\text { Fraction male } \\
\text { classmates } \\
\text { with female } \\
\text { names }(\mathrm{F}), \mathrm{F} \\
\text { x grade } 6\end{array}$ & \begin{tabular}{|l} 
Fraction \\
male \\
classmates \\
with female \\
names x \\
grade 6 \\
\end{tabular} & $\begin{array}{l}\text { Fraction male } \\
\text { classmates with } \\
\text { female names } \\
\text { (F), Fraction } \\
\text { Black male } \\
\text { classmates with } \\
\text { female names } \\
\text { (BF), F x grade } \\
6, \text { BF x grade } 6\end{array}$ & $\begin{array}{l}\text { Fraction male } \\
\text { classmates with } \\
\text { female names x } \\
\text { grade 6, Fraction } \\
\text { Black male } \\
\text { classmates with } \\
\text { female names x } \\
\text { grade } 6\end{array}$ \\
\hline $\begin{array}{l}\text { DEPENDENT } \\
\text { VARIABLE }\end{array}$ & \multicolumn{4}{|c|}{$\begin{array}{l}\text { IV COEFFICIENT ESTIMATE ON FRACTION OF CLASSMATES } \\
\text { SUSPENDED AT LEAST ONCE FOR 5+ DAYS }\end{array}$} \\
\hline $\begin{array}{l}\text { Mathematics test } \\
\text { score (national } \\
\text { percentile ranking) }\end{array}$ & $\begin{array}{l}-65.76 \\
(16.13)\end{array}$ & \begin{tabular}{|l|}
-57.55 \\
$(30.04)$
\end{tabular} & \begin{tabular}{|l}
-114.39 \\
$(8.47)$
\end{tabular} & $\begin{array}{c}-124.19 \\
(9.71)\end{array}$ \\
\hline $\begin{array}{l}\text { Child suspended at } \\
\text { least once for } 5+ \\
\text { days }\end{array}$ & $\begin{array}{c}0.94 \\
(0.15)\end{array}$ & $\begin{array}{c}0.84 \\
(0.27)\end{array}$ & $\begin{array}{c}0.98 \\
(0.08)\end{array}$ & $\begin{array}{l}1.01 \\
(0.09)\end{array}$ \\
\hline
\end{tabular}

Notes: Standard errors adjusted for clustering are in parentheses beneath coefficient estimates. Data are for students in grades three through six. 
Table 4

Sex differences in instrumental variables estimates of the effect of disruptive classmates on student outcomes

\begin{tabular}{|c|c|c|}
\hline & Males & Females \\
\hline $\begin{array}{l}\text { First stage coefficient on fraction of } \\
\text { male classmates with female names } x \\
\text { grade } 6\end{array}$ & $\begin{array}{l}-0.289 \\
(0.043)\end{array}$ & $\begin{array}{l}-0.262 \\
(0.030)\end{array}$ \\
\hline $\begin{array}{l}\text { First stage coefficient on fraction of } \\
\text { African-American male classmates } \\
\text { with female names x grade } 6\end{array}$ & $\begin{array}{c}1.085 \\
(0.110)\end{array}$ & $\begin{array}{c}1.036 \\
(0.073)\end{array}$ \\
\hline DEPENDENT VARIABLE & \multicolumn{2}{|c|}{$\begin{array}{l}\text { IV COEFFICIENT ESTIMATE ON } \\
\text { FRACTION OF CLASSMATES } \\
\text { SUSPENDED AT LEAST ONCE FOR 5+ } \\
\text { DAYS }\end{array}$} \\
\hline $\begin{array}{l}\text { Mathematics test score (national } \\
\text { percentile ranking) }\end{array}$ & $\begin{array}{r}-121.99 \\
(29.54) \\
\end{array}$ & $\begin{array}{r}-126.73 \\
(20.97)\end{array}$ \\
\hline $\begin{array}{l}\text { Child suspended at least once for } 5+ \\
\text { days }\end{array}$ & $\begin{array}{l}1.185 \\
(0.323)\end{array}$ & $\begin{array}{c}0.781 \\
(0.243)\end{array}$ \\
\hline
\end{tabular}

Notes: Regressions are estimated separately for males and females. Standard errors adjusted for clustering are in parentheses beneath coefficient estimates. Data are for students in grades three through six. 